\title{
AS FONTES ESCRITAS DO PENSAMENTO ANTROPOLÓGICO, SEUS DILEMAS E DESAFIOS - UM ENSAIO ${ }^{1}$
}

Ana Luiza Carvalho da Rocha

Viviane Vedana

Priscila Farfan Barroso

Rafael Lopo

Porque investigar, nos dias atuais, o tema da escrita e suas fontes de conhecimento para o pensamento antropológico? Que razões existem para que pesquisadores da área da Antropologia se reúnam em torno de uma discussão até certo ponto já visitada por autores clássicos, tais como Clifford Geertz (2001, 2008), Paul Rabinow (1999), James Clifford (1998) e seu cortejo de companheiros que inauguraram a antropologia pós-moderna, assim como no Brasil, pensadores como Roberto Cardoso de Oliveira (2000), entre outros. A intenção do Grupo de Trabalho sobre escrita e representação etnográfica ${ }^{2}$ do Banco de Imagens e Efeitos Visuais/BIEV, nos últimos dois anos não tem sido a de repertoriar esta controvérsia (ainda que este processo do ponto de vista epistemológico sempre se faça necessário) uma vez que esta geralmente ocorre no interior das aulas de Antropologia da graduação e pós-graduação dos inúmeros cursos de C. Sociais.

A proposta de um grupo de investigação sobre a escrita e a representação etnográfica no domínio da antropologia esta associada à necessidade de se pensar as singularidades da produção textual dos antropólogos e de não antropólogos no sentido da formação dos pesquisadores do BIEV para os sentidos e significados que a representação etnográfica comporta em termos da construção da imagem do outro. Isto porque que dentro do BIEV acolhemos acervos de fontes escritas (jornais, revistas, livros de poesia, romance e literatura em geral assim como relatos de observação participante, transcrições de entrevistas, extratos de diários de campo de pesquisadores, etc.) sobre o patrimônio etnológico da cidade de Porto Alegre e que precisam ser indexadas, catalogadas e cadastradas numa base de dados especialmente criada para esta finalidade. ${ }^{3}$

Entretanto, fora estes aspectos pragmáticos de formação de acervos documentais, há uma razão maior, mais conceitual e teórica para a existência de um grupo de investigação sobre as fontes escritas do conhecimento antropológico no interior do BIEV, e que extrapola 
as fronteiras de seus trabalhos de pesquisa. Trata-se de refletir e produzir conhecimentos sobre alguns dos condicionantes das fontes escritas para a construção do pensamento antropológico. Isto porque na história da disciplina sempre pesou sobre a escrita uma grande responsabilidade, a de expressar positivamente um pensamento que se pretende capaz não só de interpretar as culturas e sociedades humanas, mas de executar esta ação a partir de sua descrição à altura do rigor cientifico das ditas ciências exatas.

O tema da antropologia realista, do autor e da autoridade etnográfica através do questionamento do estatuto da sua representação e da fixação do significado do texto da ação social ao seu análogo (o discurso como escrita), foi abordado inicialmente por C. Geertz em termos de estilos de interpretação (1980). Posteriormente, o tema reforma agora pelas mãos dos denominados antropólogos pós-modernos e suas respectivas correntes de pensamento: a da meta-etnografia, ou seja, uma reflexão teórica sobre a etnografia como gênero literário e do antropólogo como escritor (James Clifford, 1988; George Marcus, Dick Cushman, 1982), a da etnografia experimental, preocupada com a redefinição da práxis do trabalho de campo (V. Capranzano, 1986; P. Rabinow, 1986) e, por último, a corrente mais dedicada a reformulação do projeto científico da ciência antropológica desde suas finalidades programáticas (e cujo um dos expoentes é M. Taussing, 1980). A partir daí a polêmica sobre analogia da etnografia como texto, da antropologia como crítica literária, da fonte escrita e, finalmente, do estatuto da representação etnográfica adquiriu uma densidade política nunca antes vista para o campo do pensamento antropológico.

Antes de se fazer avançar este tema um pouco mais, é importante se reconhecer que nos idos dos anos 60, o tema da função-autor ou simplesmente da morte do autor já estavam presentes em dois ensaios antológicos pós-estruturalistas produzidos por Michel Foucault (1969) e Roland Barthes (1968) no âmbito das discussões dos campos da história e da crítica literária. Vale à pena parar sob este ponto e situar esta temática e seu sentido para o caso do programa de trabalho que orienta o GT de escrita no interior do BIEV.

\section{$O$ autor em destaque e os regimes de escrita}

A polêmica de ambos os autores certamente é datada, mas é significativa aqui para se pensar certa ontologia do debate da autoria, do autor e da autoridade na produção do texto etnográfico pós anos 70. Para Foucault (1969) um autor é simplesmente um nome que assegura uma função classificatória para agrupar certos textos distinguindo-os de outros. 
Neste sentido, toda a escrita é autoral quando ela provoca uma ruptura no interior de um grupo de discursos, criando seu modo singular de ser. Na sua perspectiva a função-autor caracteriza-se pelas formas de se fazer circular, existir e difundir certos discursos dentro de uma sociedade.

Segundo Foucault (1969), o livro e a obra não são essenciais para se pensar o problema do autor porque é na ordem do discurso que esta função na escrita se processa. Ou seja, na capacidade de um discurso assumir o lugar de uma tradição, de uma teoria e até mesmo de uma disciplina (no interior da qual um autor obtém a autoridade para suas afirmações), servindo como possibilidade de atuar nas regras de formação de outros textos. Uma visão que é retomada por Barthes (1968) para quem a escrita é a destruição de toda a voz; a escrita, este espaço neutro onde toda a identidade se perde, a começar pelo corpo daquele que escreve.

A função-autor de um texto se dá, assim, na medida em que a sua escrita assume uma feição fundadora de discursividades, e se transforma em espaço portador de discursos que vão além daquilo que a originou, ou seja, seus traços temáticos e formais iniciais. O conceito chave deste ensaio de Foucault (1969) é o de formações discursivas, isto é, o autor nada mais é do que uma função associada a certo tipo de textos, definido segundo seus usos e suas práticas institucionais historicizáveis. Um autor pode ser pensando assim proprietário de sua obra e defensor de um discurso que serve de ancoragem diante dos possíveis ataques ao estatuto de suas representações.

Por outro lado, muito interessante para o que nós advogamos aqui, o autor não é o escritor real, nem o narrador, mas aquilo que "autoriza" a partilha de um texto, segundo o papel que ocupa em determinadas formações discursivas. Um tema que já havia sido mencionado por Barthes (1968) para quem dar um autor a um texto é encerrar a escritura, fechá-la sobre si mesma. Um texto escrito é um objeto singular que remete a um conjunto de regras hierarquizadas segundo seus efeitos propriamente estéticos. Se o autor está morto como instituição é porque sua importância reside no fato dele se apresentar como figura de uma relação dialógica entre o leitor e o texto.

No que tange a investigação sobre a representação etnográfica, principalmente quanto aos acervos de conjuntos documentais dos antropólogos na forma de textos, as fontes escritas estariam, assim, referidas ao seu campo literário, pois segundo Barthes (1968), os efeitos de autoridade não poderiam ser confundidos ou reduzidos às intenções do autor. No caso das 
escritas dos próprios antropólogos temos a sua referência autoral precisa: a Antropologia e as regras e normas criadas no interior de sua comunidade lingüística. A unidade de um texto, seu sentido autoral não se situaria, portanto, na origem de uma escrita (que é múltipla e plural), mas no seu destino: o leitor. Disto resulta a célebre expressão de Barthes (1968), $o$ nascimento do leitor se paga com a morte do autor. A questão de quem está falando, afinal, num texto escrito não tem assim uma resposta única, pois pode ser respondida para além da obra e do autor que a produziu historicamente.

Assim, se não se pode assegurar a autoridade de um texto antropológico fora dele próprio, muito menos se pode pensá-la desde as suas origens tendo em vista a contingência e provisoriedade de sua leitura. A escrita para Barthes (1968) impõe constantemente um sentido à medida que se percorre seu espaço, mas este sentido não se sustenta por muito tempo sem o leitor, onde o sentido se inscreve. Segundo o autor, diante das múltiplas escritas que um texto contempla é o espaço do leitor e a relação dialógica que ele constrói com o texto (em termos das instituições onde nasce e seus efeitos de autoridade) aquilo que atribui à escrita uma unidade de sentido entre outros tantos sentidos.

Como não podia deixar de ser, este cruzamento de debates do final dos anos 60 pouco a pouco, nos idos dos anos 70, vai deslizar para o caso das condições de produção de conhecimento desde as implicações do autor, da autoria e da autoridade no caso da produção textual antropológica em face do seu público leitor. Afinal, pode-se com Paul Rabinow (1999) pensar a escrita antropológica, e no seu interior o estatuto da representação etnográfica, segundo as distintas formações discursivas no interior do seu domínio disciplinar, tanto quanto pensar a autoridade etnográfica referida as instituições onde se formula o conhecimento antropológico e dos seus efeitos de autoridade.

Ao se retomar esta polêmica dos anos 60, nos perguntarmos, afinal, se o todo o autor de um texto etnográfico deve ser responsável pelo que seus personagens, pessoais reais, dizem e fazem, ou ainda, se cabe ao antropólogo integrar livremente as pessoas reais no interior do universo até certo ponto ficcional da narrativa etnográfica? O que pensar da obra de Malinowski (1978) sob os prismas da função-autor ou da morte do autor? Pensar, por exemplo, Os Argonautas do Pacifico Ocidental (1989) desde a sua função-autor, isto é, sua capacidade de, como formação discursiva, assumir o lugar de uma tradição, de uma teoria e até mesmo de um campo disciplinar. Podemos pensar esta obra de B. Malinowski desde a função-autor pelo caráter inaugural de suas formas de procedimento de pesquisa, pelas quais 
tem sido reconhecido como o pai do método etnográfico e da técnica de observação participante.

\section{As contribuições dos autores para o campo antropológico}

O ensaio de Barthes (1968) pode nos ajudar a refletir sobre a unidade dos artigos escritos e reunidos por Claude Lévi-Strauss, em Antropologia estrutural (1979), e seu sentido autoral construído a partir do público a que se destinava esta obra, ou seja, a comunidade de leitores antropólogos. O ensaio de Foucault (1969) nos auxilia a pensar a publicação Azande, Bruxaria, oráculos e feitiçaria, de Evans-Pritchard (2005), por exemplo, como resultado de uma série de operações que o texto deste etnógrafo sofre e onde a função-autor aparece precisamente na continuidade de uma tradição, a qual ultrapassa a sua vida e chega até nós em outras múltiplas leituras. ${ }^{4}$

As primeiras reflexões apresentadas por Geertz (2002) nos conduzem como antropólogos-leitores, progressivamente a levantar suspeitas sobre as fontes (escritas) daquilo que estamos lendo, se estão ou não contaminadas de elementos pessoais do autor que o escreveu. Geertz (2002) comenta as questões literárias que cercam a produção textual do conhecimento antropológico em suas relações com as questões práticas, do trabalho de campo, sendo um dos primeiros a chamar a atenção para as preocupações com as estratégias narrativas e os aparatos retóricos adotadas pelos antropólogos para descrever a sua experiência de campo para a sua comunidade lingüística de pertença, os antropólogos. Segundo Geertz (2002), o antropólogo vai a lugares, volta de lá, recolhe informações e disponibiliza estas informações para seus pares. Ou seja, a etnografia talvez seja uma espécie de escrita e o seu desafio epistemológico para a interpretação das culturas se traduz para todo o antropólogo em colocar as coisas no papel!

O autor reconhece com lucidez, neste ponto de suas reflexões, o caráter literário do conhecimento antropológico ao reportar os textos etnográficos no mundo dos livros. A credibilidade da fonte escrita encontra sua verdade na forma como ela se refere à substancialidade factual da experiência etnográfica seja pela força convincente que possui na sua adoção de uma ordem de detalhes culturais; seja pela densidade e extensão das descrições nas quais se baseia o antropólogo para suas afirmações. Por fim, Geertz (2002) admite desconhecer porque isto faz funcionar a verdade de um texto etnográfico: porque as coisas 
funcionam assim, é dificil dizer. Uma pista para abordarmos mais tarde o tema da dramaturgia contida no corpo literário dos textos etnográficos através do pensamento de Jacques Rancière (1995), entre outros.

O que Geertz (2002) aponta desconhecer (porque as coisas funcionam assim, é dificil dizer) é o que estamos procurando dimensionar aqui como tema de investigação no BIEV, com o intuito compreender os acervos que representam as fontes escritas do pensamento antropológico no sentido de reuni-las às outras fontes escritas (literárias, históricas, poéticas, lendárias, etc.) fazendo com que as mesmas, desde um núcleo semântico, possam dialogar entre si e nos ajudar a pensar a etnografia desde a escrita, e não apenas o trabalho de campo.

Re-interpretando-se a argumentação de C. Geertz (2002), podemos pensar a escrita, o espaço livresco de sua afirmação, o domínio das práticas sociais de leitura e a presença de uma comunidade específica de leitores como elementos que constituem a etnografia como texto, considerando-se suas peculiaridades cruciais (ou seja, seu caráter situacional). Reapropriando-nos da autoridade dos comentários do autor, estas seriam as condições para que os textos antropológicos sejam levados a sério e que o seu leitor ser conduzido a viver outra forma de vida que não a da sua cultura, de "estar lá" juntamente com o antropólogo, em seus momentos singulares do trabalho de campo.

Até a obra de C. Geertz (2002) o que se tinha, portanto, em termos de debate sobre as fontes escritas do pensamento antropológico eram as observações isoladas decorrente do uso das técnicas e dos procedimentos da pesquisa nas ciências sociais onde vigorava a idéia de que a etnografia ou se tratava de um mero jogo de palavras ou não valia o esforço de uma empreitada de análise mais detalhada, pois bons textos antropológicos são simples e despretensiosos. ${ }^{5}$ Sob este enfoque é interessante nos determos em duas afirmações de C. Geertz (2002) sobre as peculiaridades da etnografia na forma de texto, e que nos estudos da fonte escrita no BIEV interessam particularmente. A primeira diz respeito ao paralelismo entre o encontro etnográfico e o encontro com a página (entrar em seus textos - isto é, introduzir-se representacionalmente - talvez seja tão difícil para os etnógrafos quanto entrar numa cultura - ou seja, penetrar nela imaginativamente); a segunda que trata da polêmica entre o estatuto científico da escrita etnográfica e sua base biográfica (eu estive lá, isto aconteceu comigo).

$\mathrm{O}$ autor critica a posição que considera serem estas questões apenas problemas 
decorrentes das negociações entre o eu e o outro e não como derivados das negociações entre o eu do antropólogo e o texto. Acreditamos-se no interior de um texto "autoral" que o autor não sofre constrangimentos oriundos do corpo da letra, mas, ao contrário, que o corpo da letra apenas está lá para afirmar singularmente a presença do si-mesmo do antropólogo-autor traduzindo finalmente algo que lhe é próprio. ${ }^{6}$

A partir da concepção de J. Rancière (1995) do corpo da letra como sendo o que gera esta inquietação/perturbação do texto podemos considerar que é na estreita colaboração entre ambas as instâncias onde desponta o mal estar do autor como fator determinante da produção dos textos científicos em Antropologia. Uma inquietação que não surge apenas $d a$ relação do eu do antropólogo com o texto ou com o outro, mas se origina precisamente na forma como o corpo da letra problematiza os limites da partilha do sensivel que encerra todo o ato de introduzir-se representacionalmente numa determinada experiência etnográfica, seja através da escrita, seja da leitura. ${ }^{7}$

O desafio de se pensar o significado desta expressão introduzir-se representacionalmente exige que nos afastemos de qualquer possibilidade de navegar no senso-comum no que diz respeito às noções de autor e do autoral. A idéia ordinária, antes da controvérsia conduzida por R. Barthes e M. Foucault, é a de que um autor é alguém que integra à escrita algo da ordem pessoal, sendo a produção textual autoral o resultado do trabalho de um ser que é senhor e mestre de seus próprios pensamentos e precursor de suas próprias idéias. Esta fórmula senso comum de se pensar a figura do autor apresenta um grande problema uma vez que um texto, ou qualquer texto, não é regido apenas pela consciência de um autor, nem é reservatório apenas de suas leituras, lembranças e fontes pessoais de informações. Um texto, ainda que autoral, se constrói na relação direta de seu autor com um campo de conhecimento, logo, está repleto das tensões entre invenção e tradição, atos absolutamente complementares na ordem da construção da escrita, mesmo aquela que se queira autoral - autoral no sentido seja de M. Foucault (inaugural de uma formação discursiva), seja no sentido R. Barthes (dos teatros da linguagem).

\section{Sem perder de perspectivas os desafios da etnografia como escrita}

O objetivo de uma pesquisa em torno da produção textual em Antropologia para o tema da construção da representação etnográfica cerca, portanto, um vasto espaço de 
problemas que, em algumas vezes, o ultrapassa. Com este artigo, fruto do grupo de trabalho do BIEV dedicado a esta área de pesquisa, não se pretende esgotá-lo, mas sim explorá-lo como um campo fértil de investigação não só para a produção do pensamento em Antropologia, mas também de novas formas de práticas de escrita no âmbito do espaço livresco (de teses, dissertações, artigos, ensaios ou monografias). Tendo em vista as outras fontes documentais com as quais trabalha o BIEV (vídeo, som e fotografia), não se trata de pensar a escrita por oposição às outras formas de representação etnográficas, mas de se refletir sobre o vigor da escrita antropológica na contemporaneidade como espaço de produção de etnografias, em seu diálogo intenso e profundo com o processo de trabalho de campo. ${ }^{8}$

Portanto, interessa aqui se pensar as relações diferenciais através das quais as inúmeras práticas do trabalho de campo dialogam com a produção do texto etnográfíco publicado (teses, dissertações, artigos) e as modalidades de escrita preliminares tais como os cadernos de notas, o diário de campo, as descrições de observações participantes, os roteiros de entrevistas assim como com a passagem das formas orais de transmissão de conhecimento para o corpo da letra. Toda esta preocupação se dirige, ao final, para a produção de novos experimentos etnográficos a partir do manejo da escrita sem, entretanto, nutrir qualquer intenção de legitimar este ou aquele modelo ou gênero de escrita, mas tendo como projeto a compreensão mais aguda do campo da disciplina antropológica na contemporaneidade.

Neste tópico é importante se ressaltar que, sob a ótica da autenticidade, legitimidade e autoridade, a produção textual dos antropólogos, e os seus informes etnográficos "realistas", embora tenha sofrido ataques sérios por suas marcas de instituição literária à serviço de objetivos científicos positivistas (G. Marcus \& D. Cushman, 1991, p. 175-176), na contemporaneidade se afirma cada vez mais, paradoxalmente, num espaço expressivo de luta da Antropologia em defesa dos direitos humanos no âmbito das comunidades culturais com as quais trabalha. É a produção textual dos antropólogos aquela na qual irá se configurar o estatuto jurídico legal de suas identidades coletivas - vide os casos dos laudos antropológicos que invadem a cena social no Brasil, nas últimas décadas, abordados recentemente em publicação da Associação Brasileira de Antropologia (Leite, 2005). ${ }^{9}$

Ou seja, a escrita antropológica ao contrário do que se pode pensar se consolida na contemporaneidade como um campo singular de disputa política para os povos não ocidentais desde suas relações estreitas com a comunidade lingüística dos antropólogos. Nas ações 
afirmativas destes povos a escrita confere aos fatos etnográficos um caráter de credibilidade e de fidedignidade ao posicionar o antropólogo cada vez mais como mediador cultural de direitos coletivos de comunidades e/ou grupos os quais, ainda que sejam detentores dos códigos de leitura e escrita, não tem por hábito circular nas esferas da vida social onde o corpo da letra costuma afirmar seu poder de vida e de morte.

Pela natureza política do direito moderno e diante dos desafios do multiculturalismo, ironicamente, as fontes escritas, o espaço livresco e suas jurisdições têm se transformado, para o pensamento da antropologia contemporânea, em espaços por excelência seja de critica à liberdade individual aplicada à concepção coletivista das sociedades com as quais o antropólogo interage, seja de ataque ao primado do direito de propriedade e ao caráter opressivo dos fundamentos do direito do Ocidente moderno no que tange aos direitos comunitários destas mesmas sociedades.

Esta polêmica da autenticidade e autoridade das fontes escritas na representação etnográfica do outro, de seus valores culturais e da natureza política de sua identidade, se fora de campo, na esfera das decisões dos Estados-Nações (das suas políticas da escrita), onde a produção textual do antropólogo circula, parece certos contornos claros, dentro de campo, e nos enquadres das folhas de uma tese ou de livro, continua tendo os seus limites borrados e esfumaçados..$^{10}$

Logo, é importante se situar esta polêmica em termos dos regimes da escrita nos quais as produções textuais dos antropólogos se encontram referidas. Ou seja, de um lado a escrita situada no interior da vida social ocupando uma multiplicidade de modos e de lugares (da tribo e da fábrica às universidades), e de outro, a escrita situada na esfera de jurisdição do Estado, de suas decisões e deliberações em conformidade com o espírito de suas leis. No primeiro lugar, o antropólogo se vê as voltas com a legitimidade de sua autoridade, no outro, ele, ao contrário, se investe da figura do representante autorizado para falar em nome de.

É o momento de se refletir, portanto, nas palavras de J. Rancière (1996, p. 10), sobre o ponto de desentendimento entre ambas as situações no que se refere à voz do antropólogo. Trata-se de procurar, para cada um destes lugares, o sentido e a propriedade das palavras escritas dos antropólogos, naquilo que, ao retomar o livro I da Política em Aristóteles, J. Rancière aponta, ou seja, "o que a palavra manifesta, o que ela torna evidente para uma comunidade de sujeitos que a ouvem, é o útil e o nocivo, e consequentemente, o justo e o 
injusto".

Segundo este autor, a posse da palavra (logos), que difere da simples voz, manifesta uma aesthesis compartilhada - espaço do justo e do injusto que ela configura (figura com) - e desde onde se funda uma comunidade, a dos sujeitos que a escutam e dividem entre si o seu sentido. Poderíamos situar que é precisamente na posse da palavra (logos), em termos de G. Simmel (1935) que a dimensão do conflito se revela como produtor de sociação, veículo da própria vida social. Na posse da palavra temos a linguagem humana articulada coletivamente à procura da sua propriedade de enunciação, a qual sempre traz consigo o desentendimento como campo de possibilidades das formas de sociação que gera.

Interessante recolocar esta controversa para o caso da escrita etnográfica. Na textualização de seu trabalho de campo sobre outro e a sua cultura, o mal-estar da etnografia como texto tem sido associado freqüentemente à confusão, à imprecisão e até mesmo à impropriedade da representação etnográfica no momento em que o justo e o útil da cultura do outro pode se re-apresentado como injusto e inútil não só para a comunidade lingüística dos antropólogos, mas para a sua sociedade de pertença. Seguindo-se a argumentação de J. Rancière, poderíamos interpretar em tal situação a inquietação/perturbação do corpo da letra no interior da produção textual do antropólogo estaria associada às questões do mal-entendido e do desconhecido em face da sua alteridade ao "nativo" e a sua cultura. Para J. Rancière (1996, p.12), "os casos de desentendimento são aqueles em que a disputa sobre o que se quer dizer e falar constitui a própria racionalidade da situação da palavra".

Neste momento, nada mais apropriado para se pensar, então, as diferenças que ocorre entre, por um lado, a ausência de um objeto comum que reúna o logos das palavras escritas do etnógrafo e os sons articulados da voz do "nativo" (a situação anteriormente descrita) e, por outro, a ausência de um objeto comum na interpretação do texto etnográfico entre os antropólogos. ${ }^{11} \mathrm{Ou}$ seja, o desentendimento inerente à própria racionalidade da situação da palavra, e que lhe é próprio, se aplicaria mais claramente ao regime da escrita onde a palavra do antropólogo esta referida ao campo dos saberes letrados e menos a sua escuta da voz de outro. Nesta segunda situação, o que está em jogo não é alteridade da voz do outro, recolhida em campo, destinada a ser escutada de uma forma diferente daquele que a fala (malentendimento), mas as disputas no interior da comunidade antropológica sobre o que quer dizer este outro para/entre os próprios etnógrafos. $\mathrm{O}$ desentendimento se refere às condições 
internas da produção textual dos antropólogos quando a qualidade comum de suas palavras em relação a sua comunidade lingüística de pertença tem seu sentido com-partilhado afetado.

Sob este aspecto, ironicamente, o texto etnográfico (mais do que o trabalho de campo) contempla uma ação política, pois, é no espaço do texto escrito e desde a racionalidade adotada pela palavra do etnógrafo sobre o pensamento "nativo" que o antropólogo é desafiado a articular um comum de sentido a ser compartilhado entre as respectivas sociedades e culturas. Portanto, o mal estar da etnografia como texto (do introduzir-se representacionalmente) trata, assim, dos desacordos do sentido atribuído pelos antropólogos à voz do outro, e isto, no interior de um logos que desde a origem não pertence ao "nativo". Agrega-se a isto outro desafio, o da aceitação de que este sentido comum acordado entre os antropólogos a palavra do outro não deriva de algo que é próprio ao outro ou a sua cultura, mas que se coloca no plano dos conceitos e teorias da própria antropologia. ${ }^{12}$ Paradoxalmente, a etnografia na sua forma textual ao conduzir, hoje, cada vez mais os antropólogos ao desentendimento acaba por contribuir para o exercício de as suas bases epistemológicas.

A ausência de uma reflexão quanto à presença do desentendimento no interior do corpo da letra das etnografias contemporâneas, por um lado, tem provocado suspeita em torno do comum de sentido que reúne a comunidade lingüística dos antropólogos, suas fragilidades e conflitos. Por outro, o antropólogo ao falar (melhor seria dizer escrever) em nome da palavra por ele possuída do nativo (e em sua defesa), na esfera de jurisdição do Estado desloca o desentendimento para a esfera de suas decisões e deliberações, denunciando a ausência de um comum de sentido entre os laudos antropológicos e o espírito das leis da sua sociedade de pertença. Obviamente, que ambas as situações podem ser reunidas se pensarmos o deslocamento do desentendimento no plano dos laudos e contra-laudos produzidos pelos antropólogos no que se refere à presença do conflito como força e motor das formas de sociação no interior de sua própria comunidade lingüística de pertença. O que reforça mais uma vez o que queremos aprofundar aqui, qual seja o debate sobre o comum de sentido da escrita etnográfica como um fenômeno que é a expressão do político no interior da construção do próprio pensamento antropológico. Um fenômeno que põe em jogo a própria racionalidade dos saberes e fazeres do antropólogo, e tudo aquilo que sua comunidade lingüística pensa lhe ser próprio. 
Bem mais parece ser o desafio de se pensar o mal-entendido ou desconhecido que cerca a etnografia como texto, em sua estreita interdependência com a experiência do trabalho de campo. Diferente da situação de vulnerabilidade e risco que o desentendimento pode provocar as formas de produção do pensamento antropológico, o mal-entendido ou desconhecido não se refere a uma situação em que o sentido do que está sendo dito e ouvido pelo antropólogo se polemiza com a racionalidade do logos de sua comunidade lingüística. Ao contrário, o sentido do que está sendo dito e ouvido contempla uma tensão inerente ao encontro etnográfico e onde a palavra viva do outro para ser transmitida necessita se submeter ao corpo da letra do antropólogo. A tradução da palavra viva para o corpo da letra, órfã, ao mesmo tempo muda e falante é que engendra na escrita etnográfica o mal-entendido e o desconhecido. ${ }^{13}$

Um tema nada original se pensarmos que em meados dos anos 70, Michel de Certeau (2002) abordou com propriedade o caráter etno-gráfico e as formas de produção de conhecimento em antropologia a partir do tema da oralidade (a voz do nativo) e da escrita (a palavra). $\mathrm{O}$ autor assinala de forma perspicaz algumas das especificidades das fontes escritas na formulação da etnografia desde a produção textual dos antropólogos - e que vamos nos servir aqui para re-situar, noutros termos, o tema as diferenças entre o desentendimento e o mal-entendido e seus efeitos para uma reflexão sobre a fonte escrita da representação etnográfica. Segundo De Certeau as fontes escritas do pensamento antropológico comportam as seguintes especificidades: a oralidade (forma de comunicação por excelência do diálogo etnográfico na situação de trabalho de campo), a espacialidade (o conhecimento antropológico emana dos lugares por onde circula o etnógrafo numa cultura em busca da voz do nativo), a alteridade (dado no corte cultural que se apresenta entre o etnógrafo e o outro) e, finalmente, a inconsciência (uma vez que sobre o outro são enunciadas palavras que lhes são estranhas, desde um lugar que não o seu de pertença). Segundo o autor, inspirado na concepção de etnologia em Lévi-Strauss (as condições inconscientes da vida social), a antropologia nasce da palavra viva do nativo o qual, por sua vez, desconhece as leis que silenciosas a regem; a palavra viva vai se transfigurar em palavra escrita, organizada num espaço outro que não o da oralidade.

As idéias de Michel de Certeau (2002) sobre a etno-grafia podem nos auxiliar a precisar melhor o que estamos abordando aqui como linha de investigação. Inicialmente 13 
ressaltamos que o autor tem por preocupação reunir uma reflexão que abarca o diálogo entre história e antropologia (etnologia) para melhor refletir sobre a determinação mútua entre o oral e o escrito. E esta é apenas uma das partes de nosso imenso problema como antropólogos. Outro desafio, não trilhado por M. de Certeau, mas por outros historiadores da cultura como Roger Chartier (1999, 1996, 1996a) seria o de se pensar a posição da escrita em face da oralidade diante da não disseminação do corpo da letra no interior das próprias sociedades ocidentais moderno-contemporâneas (sociedades da escrita). ${ }^{14}$ Retornando Michel de Certeau, e segundo seu ponto de vista, os desafios da Antropologia residiriam na peculiaridade da escrita etno-gráfica e dos processos escriturísticos organizarem a palavra viva numa racionalidade particular, atribuindo com isto consciência à natureza inconsciente da cultura do outro. A escrita etno-gráfica procuraria, então, posicionar-se como uma palavra que fala no lugar do outro, e destinada, entretanto, a ser escutada de uma forma diferente daquele que a pronunciou.

Michel de Certeau (2002) apresenta, sob este ângulo, claramente um dos dilemas do mal-entendido para o antropólogo, ou seja, ele fala para um grupo de letrados o que devem ler sobre o seu contato com o outro. Sem dúvida, como vimos através de C. Geertz (2002) a marca do "eu estive lá" da antropologia realista é fundamental, mas para o historiador, isto se deve ao fato de ela ter um público específico: uma sociedade da escrita que se interessa por esta experiência antropológica. Nos termos de J. Clifford, (1991) a racionalidade da palavra escrita na qual se apóia o antropólogo está depositada nas leis das representações científicas de sua época. Do ponto de vista de Michel de Certeau (2002, p. 214), a etnologia exila a voz do outro porque a coloca fora do seu campo de enunciação, transformando-a em algo exótico, o que não a invalida uma vez que o seu sentido continua aprisionado, como etno-grafo, ao campo da cultura que a produziu; o que fazemos, na verdade, é reduplicar seu efeito. ${ }^{15}$

\section{A figuração e o figurativo da fonte etnográfica}

A esta altura vale à pena situar novamente a expressão introduzir-se representacionalmente para o caso do texto etnográfico. Este aspecto aparece claramente nos comentários de C. Geertz sobre a estrutura da edição do livro de Raymond Firth, We, the Tikopia, de 1936, a presença do autor nas notas e apêndices, etc. assim como a introdução de 
B. Malinowski à sua obra clássica Os argonautas do pacifico ocidental, as quais reúnem os pormenores do "isto aconteceu comigo" levando o leitor, principalmente no caso de Raymond Firth, à convicção de que o que esta lendo sobre os tikopianos pode ser aceito como fato.

Apesar dos comentários deste autor sobre a produção textual de outros colegas, e conhecendo-se as criticas dos pós-modernos a própria produção da etnografia como texto na obra de C. Geertz, torna-se evidente que o potencial de interpretações errôneas ou equivocadas contidas na representação etnográfica do outro veiculada pelo antropólogo em seus estudos e monografias independente da linguagem ou suporte adotado pelo etnógrafo. Os mal-entendidos, nos termos que queremos abordar aqui, ocorrem apesar de todo o rigorismo metodológico adotado pelo etnógrafo em campo e do processo mais cuidadoso e diligente da ética do antropólogo no momento da captação e do registro de outra cultura. A escrita etnográfica, na tentativa do antropólogo situar-se representacionalmente no mundo do outro desde o corpo da letra, traz consigo esta perturbação inerente às formas de construção do pensamento antropológico, isto porque ao exilar a voz do outro e colocá-la fora do seu campo de enunciação, a palavra "nativa" não fica restrita apenas a racionalidade do $\log o s$ da escrita antropológica e das interações dos antropólogos com os grupos por eles pesquisados. Em sua modalidade contemporânea esta situação se agrava diante do papel que pode vir a ocupar o antropólogo no interior das dinâmicas de mundialização das culturas.

Aceitando-se o risco e procurando complexificar semelhante quadro, reconhece-se que um dos primeiros aspectos a ser ressaltado com relação ao lugar da fonte escrita para a construção da representação etnográfica na formação de um antropólogo é que, no espaço livresco, o corpo da letra para se tornar vida necessita ser lido. Aprendemos a ser antropólogos tanto indo à campo quanto lendo as obras dos clássicos (modernos e pósmodernos, e suas formações discursivas) e ensaiando nossas etnografias. Insistimos aqui que não há sentido em se contrapor à fonte escrita como suporte do conhecimento antropológico sob o risco de se advogar que o etnógrafo abdique da perturbação e do mal-estar que representa a função de escritor, e, da mesma forma, a função de leitor no campo da produção dos saberes antropológicos.

Para finalizar este artigo, vamos ensaiar um excurso "biográfico" dos regimes de escrita que a tradição antropológica herdou. Neste sentido, a fonte escrita da representação etnográfica não é só depositária da representação do outro, através do registro do próprio pensamento do antropólogo em sua experiência vivida no mundo do outro. Ela não está 
relacionada apenas com as questões da autoria, do autor e da autoridade que cercam o mundo da escrita, mas também com outras formas de transmissão do conhecimento a ela vinculadas (no caso o da comunidade lingüística dos antropólogos) e que estão referidas ao mundo das práticas culturais da leitura e a figura do leitor no Ocidente.

Seria, portanto, contraditório combater a fonte escrita na construção do conhecimento antropológico a partir do que é próprio do campo de suas práticas sociais mais tradicionais (de leitura e escrita), ou seja, através do corpo da letra. E paradoxal seria apoiar-se nos conhecimentos transmitidos pelo espaço livresco onde se situam os clássicos do pensamento antropológico tais como As estruturas elementares do parentesco de C. Lévi-Strauss (1982), Os Nuer de Evans Pritchard (1999), Os argonautas do pacífico ocidental de B. Malinowski, Negara de C. Geertz (1981) e mesmo do Balinese's Characters(1962), de M. Mead e G. Bateson, entre outros para combater a fonte escrita do pensamento antropológico.

Afora estas questões, a crítica ingênua à fonte escrita do pensamento antropológico tem seu lado mais sombrio, qual seja, a idéia de em prol da pretensa estabilidade da representação etnográfica, estaríamos reivindicando o abandono das fontes escritas como espaço significativo da produção do pensamento antropológico. Um ato que nos levaria inevitavelmente senão a eliminar, pelo menos a questionar o espaço livresco como um dos lugares onde tais saberes e fazeres se difundem. Dando as costas às fontes escritas da produção do conhecimento antropológico certamente acabaríamos eliminando os atos de leitura como fundamentais para a formação do ofício de antropólogo. Uma coisa não vem sem a outra porque ambas se complementam como espaço de construção de conhecimento; não posso abdicar da função de escritor sem aniquilar com a do leitor e este, por sua vez, não existe sem a o papel da escrita. Pensar nisto faz com que se evite cair na postura obscurantista de se "queimar" livros tendo em vista a aventura (e não os limites) que as fontes escritas carregam historicamente para a construção da representação etnográfica.

A referência a aventura do corpo da letra para o vigor do pensamento antropológico nos impõe aqui pensar, para nós, etnógrafos, acerca das origens da potência da noção de figura e não do figurativo para o caso da fonte escrita do conhecimento no campo dos saberes e fazeres das sociedades ocidentais assim como da força de ilustração do Verbo nas culturas monoteísta de tradição da escrita para a construção da etnografia como texto. Novamente aderimos às idéias seminais de J. Ranciére (1995) segundo as quais em suas origens a letra tem por aventura figurar e advogamos aqui que é, precisamente, através desta aventura que a 
escrita antropológica tem por pretensão introduzir-se representacionalmente no mundo do outro.

O conceito de figura aparece aqui não no sentido de uma imagem a ser convertida em seu sentido, mas de um corpo que anuncia outro corpo, pois para ter seu corpo da verdade a escrita necessita que alguém lhe encarne como verbo (Ranciére, 199, p. 48). Com este autor podemos pensar que todo o "problemático" literário da escrita antropológica guardaria para si esta dimensão de uma leitura figural, ou seja, o reconhecimento de que no interior do corpo da letra morta das etnografias dos antropólogos habita a palavra viva do outro obtida na experiência do antropólogo em campo, no mundo do outro. Certamente estamos nos referindo aqui a uma noção particular do figurativo e da figura que vale a pena nos determos com mais acuidade.

Para prosseguir em seus comentários para pensar a noção de figura como referida a uma arte de fazer e a promessa de uma verdade, retomamos os comentários de J. Rancière (1995:59) sobre as sagradas escrituras e o nascimento da filosofia cristã. Com o autor, podemos compreender o deslizamento da poética do texto religioso (função figural do corpo da letra) para a poética do texto romanesco (função figurativa do corpo da letra) e onde, segundo o autor, o caráter figurativo do corpo da letra tende a apagar a sua dimensão figural, e ao apagá-lo conserva, entretanto, seu poder de atestar um corpo. ${ }^{16}$ Acreditamos atingir a compreensão de parte daquilo que C. Geertz (2002) reconhecia como sendo a potência da palavra escrita como expressão etnográfica.

Não é por acaso que este autor assim como M. Foucault (1996), ainda que de forma diversa, vai se apoiar no personagem de D. Quixote (o louco da letra) para apontar na falha entre o corpo e a letra o nascimento do romance moderno situado no interior do jogo sistemático entre as figuras do autor e do narrador que este regime da escrita favorece - algo que num círculo de interpretação, nos jogaria aos comentários sobre a função-autor ou a morte do autor, no início deste ensaio. Don Quixote, no romance de Cervantes, é um personagem que reúne todos os signos e os preenche de semelhanças que não cessam de proliferar. Sob uma ótica diferente de J. Rancière, para M. Foucault, o romance. As aventuras de Don Quixote trazem à tona, para a épistémè do mundo moderno, o problema de que as palavras deixam de ser a prosa do mundo, pois as semelhanças e os signos perderam seu sentido; as palavras não são mais o que eram. As palavras erram em aventuras sem conteúdos, 
sem similitudes para preenchê-las. Possíveis semelhanças entre as palavras e as coisas reapresentam formas de saber consideradas fontes de erro, perigosas, pois geram confusões. $\mathrm{O}$ autor observa que para a épistèmé do século XVI, a natureza como um jogo de signos e de semelhanças se fecha sobre ela mesma, segundo a figura duplicada do cosmos - microcosmo e macrocosmo e seus efeitos de duplicação. ${ }^{17}$ Conhecer é ir da marca visível (a cifra) aquilo que é dito nelas, sem o qual a assinatura é letra muda. ${ }^{18} \mathrm{O}$ ingresso na épistèmé do séc. XIX traz consigo, na perspectiva de M. Foucault, a "démarche" critica ao papel representativo da linguagem. Ela se interroga sobre ela mesma a partir de sua função. O verbo, afirma ele, indica que o discurso reside na palavra empregada; ele é o discurso de um homem que não concebe somente os nomes, mas os julga. Do interior dela própria a linguagem afirma algo, e sustenta todo o discurso possível. Fala-se agora do ser representado na linguagem, poder da palavra que articula um sistema de signos em direção do ser do que é significado.

Observação similar faz G. Durand em seu livro Science de l'homme et Tradition, pour un nouvel esprit anthropologique (1979) apesar de situar esta polêmica tratada por M. Foucault a partir da grande erosão "histórica" da figura do homem na filosofia ocidental e de suas catástrofes metafísicas, o que para ele se inaugura em épocas mais remotas, mais precisamente no século XII ${ }^{19}$. Para autor, no Ocidente, esta primeira catástrofe metafísica resulta das ambições do imperialismo temporal da Igreja e do papado em eliminar a gnose como acesso a palavra divina contida no Verbo das escrituras. Seus esforços se deram no sentido de separar cuidadosamente a função humana do conhecimento e da revelação cujo uso e interpretação são do domínio reservado dos clérigos, e do qual resulta a recusa direta da alma humana ao seu modelo divino e da figura humana como intermediária de Deus. ${ }^{20}$ Para G. Durand, nasce, assim, a "razão" - sob a forma de adaptação objetiva a um universo separado do homem tanto quanto sob a forma positiva de submissão aos "fatos" históricos que estende seu império aos limites da psiqué do Ocidente e da figura do homem da civilização.

A segunda catástrofe transcorre no século XVI, no interior dos movimentos contra ditadura do magistério dogmático da Igreja, quando se oficializam os dualismos constitutivos da filosofia ocidental, não só o mundo sagrado separado do mundo profano, mas o corpo 
separado da alma, a res extensa separada da res cogitans. Finalmente, a terceira catástrofe ocorre ao longo dos séculos XVII e XVIII e com ela se reduz pouco a pouco o sagrado ao profano, a res cogitans à res extensa, instaurando-se pela via mecanicista e determinista a visão de que a unidade da figura humana é dada e postulada na afirmação no "Eu penso". Ou seja, o mundo se unifica através do "modelo" de cogito unificado, valorização ideal de procedimentos vazios do cogito e onde "re-presentar", "falar", "classificar" e "trocar" se constituem modalidades de épistèmé. ${ }^{21}$

Para fecharmos o campo de sentido de artigo, já temos aqui o suficiente para retornar os pensamentos de J. Rancière (reunidos aos comentários de M. Foucault e de G. Durand), sobre o tema da figura, do figural, do figurativo. Na palavra escrita romper o figurativo da sua potência figural é tratar a ficção como letra à qual falta o corpo de sua verdade. O louco da letra é, então, um D. Quixote, alguém que se entrega a loucura de acreditar em histórias. Temos então que o figurativo aqui toma outra forma, não apenas o do visível, mas do sensível! Seremos nós, antropólogos herdeiros desta aventura do louco da letra ao creditarmos uma potência figural as nossas etnografias, realistas, impressionistas ou quaisquer que sejam elas?

Segundo J. Rancière, diante da pergunta sobre a falsidade ou a verdade do livro, ou quais são os livros falsos e quais são os verdadeiros, devemos nos indagar o que é que nos atribuir falsidade a um livro? Uma velha questão exegética, pois para compreender o corpo de verdade da letra necessitamos remetê-los ao seu corpus tradicional de "verificação" das histórias, ou seja, enquanto verdade do corpo que encarna o verbo, sustentando sua evidência. Não podemos ignorar a verdade de um mundo veiculada pelos livros sem referência ao universo de sua existência (ao corpo da letra) e a existência daquilo de que falam.

Para J. Rancière a leitura figural de um texto encontra sua expressão plena, na civilização do Ocidente, na exegese cristã das Escrituras. Segundo J. Rancière (1995, p. 47:58), é sempre preciso um corpo para provar a Escritura tanto quanto é sempre preciso a Escritura para provar que aquele corpo em questão é o corpo mesmo. Uma afirmação que nos conduz a pensar o espaço livresco (Chartier, 1996) e as práticas de leitura e escrita configurando, através do corpo da letra, um comum de sentido que funda uma comunidade em especial, por exemplo, a dos antropólogos. Ainda que se considerem as diferentes formas de se pensar o figural da história de suas comunidades, o caso dos judeus, cristãos e 
muçulmanos e seus Livros Sagrados pode ser aqui um exemplo dos dilemas da tradição do literário que a escrita etnográfica em Antropologia herda para si.

O primeiro dilema se refere ao princípio, seguindo-se o J. Rancière (1995, p. 54), da teologia do corpo literário no sentido de que a letra do livro figura a presença e o sofrimento do Verbo, do filho de Deus, numa transferência de significado que atribui ao corpo da letra o suplemento de verdade que lhe é necessário - podemos situar aqui a obrigatoriedade de todo o antropólogo reviver a tradição do trabalho etnográfico, seus percalços e imponderáveis. Outro dilema refere-se ao segundo princípio, o da leitura figural do deserto, ou seja, aquela em que a condição do sentido do texto e do corpo da letra está dada num novo corpo, o corpo daquele que sofre a sua verdade (a espiritualidade hermética) e encarna o Verbo - podemos colocar aqui a condição iniciática (isolamento) que representa toda produção dos saberes e fazeres antropológicos associados a um processo de isolamento que o mergulho na cultura do outro representa - e que R. Da Matta (1981) menciona como as duas viagens do antropólogo, a heróica e a xamânica). Obviamente a escrita antropológica contemporânea herda estes dilemas, mas não se reduz a eles.

No BIEV, a investigação sobre a fonte escrita da representação etnográfica parte da afirmação central de J. Ranciére $(1995$, p. 7) para quem antes de ser o exercício de uma competência, o ato de escrever é uma maneira de se ocupar o sensivel e de dar sentido a esta ocupação. A pesquisa com a fonte escrita do pensamento antropológico, portanto, traz à tona a estrutura social dos saberes e fazeres deste campo do conhecimento e acaba devolvendo a comunidade lingüística dos antropólogos o estudo de seu próprio sistema de representação, confrontando o etnógrafo com os privilégios da organização cultural desde onde fala. Protestar que a fonte escrita não diz a verdade só nos mostra a utilidade da escrita para própria construção de reflexividade em Antropologia e a confiança que nela podemos ter, ainda hoje, na contemporaneidade, como exegese dos saberes e fazeres do etnógrafo em campo, apesar dos ataques a ela desferidos.

Escrever é, portanto, para o antropólogo um ato que remonta a uma tradição de produção de conhecimento. Qual é afinal o lugar que a escrita constitui para nós como intérpretes de culturas, não apenas espectadores? Há um sentido político e social inerente ao ato de escrita antropológica. Nos termos de Michel de Certeau (1995, p. 80), o corpo da letra na produção de conhecimento em Antropologia sempre nos interroga como etno-grafo de onde falamos e o que se pode dizer (ainda que se tente resolver a função social da cultura 
erudita no interior da prática antropológica apenas com o debate em termos das questões formais da produção textual). Sabiamente este autor conclui (1995, p. 82): a linguagem instala-se nessa ambigüidade entre aquilo que ela implica e aquilo que ela revela, e a linguagem escrita empregada pelo antropólogo não foge a regra.

Especialmente nisto reside à singularidade da fonte escrita para a construção da representação etnográfica: um espaço aberto de partilha que apesar de contemplar um ato de distinção, nem por isto, podemos dela nos servir para atingir a redenção de nossos pecados de elite. Admitir o caráter condicional da existência do literário no interior da fonte escrita do pensamento antropológico e na delimitação da representação etnográfica que aparece no corpo dos livros escritos pelos antropólogos não significa apenas levantar a controvérsia dos acordos e desacordos na existência de regras objetivas para a partilha do logos que funda a racionalidade da ciência antropológica para além de sua comunidade lingüística de pertença (da letra emancipada do ato da palavra) nem da presença de um arbitrário de julgamento de valor na partilha de tal logos reunindo o mundo do etnógrafo e o mundo do outro.

Mais do que isto, há algo o caráter condicional da existência do literário no interior da fonte escrita do pensamento antropológico e na delimitação da representação etnográfica e que nos interessaria continuar a refletir que é a figura da letra como parte integrante do literário que se encontra presente na escrita etnográfica tendo em vista o lugar que a verdade dos livros ocupa no mundo contemporâneo: o mundo é tecido de livros: não apenas imaginário partilhado, mas textos que são todos compartilhados da mesma maneira J. Rancière (1995: 68) ${ }^{22}$. Entretanto, este se pretende o tema para outro artigo.

\section{Notas}

Este artigo só foi possível graças às bolsas obtidas de Iniciação Científica/FAPERGS e CNPq, bolsa de Doutorado /CNPq e bolsa de Pesquisado/CNPq pelos autores deste ensaio. Entre os pesquisadores do BIEV integra atualmente o estudo deste tema os alunos de graduação Ana Paula Parodi, Rodrigo Ramos, Patrick Barcellos, Anelise Guterres, Stephanie Bexiga, Caetano Sordi e Desirée Sant'anna com quem dividimos atualmente as pesquisas e os estudos do Grupo de Trabalho sobre escritas etnográficas.

2 O Grupo de Estudos sobre escrita etnográfica faz parte do Banco de Imagens e Efeitos Visuais, do PPGAS/UFRGS, com a coordenação geral da Profa. Dra. Cornelia Eckert.

${ }^{3}$ Tais acervos resultam de fundos de origens distintos conforme as pesquisas e as coleções etnográficas de cada investigador no domínio da pesquisa que o BIEV desenvolve. Em especial, a montagem das coleções etnográficas ocorre a partir do estudo de fontes escritas que, organizadas em conjuntos documentais a partir de certas categorias e palavras-chave, as quais formam um thesaurus, um vocabulário controlado extraído da pesquisa do BIEV, com a finalidade de descrição de tais documentos como totalidade de sentido. 
${ }^{4}$ Este processo é claramente apresentado, sem a necessária concordância com as premissas e as conclusões de ambos os autores, por Geertz, na introdução do seu livro Vidas e Obras, o antropólogo como autor (Geertz, 2002), publicado nos EUA, nos anos 80, sobre a obra de B. Malinowski, Os Argonautas do Pacífico Ocidental (1989) e de Evans Pritchard, Os Nuer (2005).

${ }^{5} \mathrm{Na}$ verdade, o autor contesta estas posições ao apontar, segundo nossa re-interpretação, a importância das políticas da escrita em Antropologia, ao reconhecer que é através do corpo da letra que a Antropologia tem conseguido divulgar as situações críticas sob as quais vive uma grande parte de sociedades e culturas não ocidentais no Brasil, na África, na Índia, na Austrália, etc.

${ }^{6}$ A idéia senso comum é que a figura do "autor" associada à fonte escrita do pensamento nasce da busca do simesmo daquele que escreve no interior de certo campo de conhecimento. Numa visão ingênua da escrita, ser um "autor" é inscrever numa determinada área de conhecimento sua assinatura, registrando através do texto a sua relação particular com o mundo.

${ }^{7}$ Do ponto de vista da investigação que realizamos no BIEV, pensamos é que não é possível dissociá-los (o eu e o outro/ entre $o$ eu do antropólogo e o texto) tal o nível de solidariedade que existe entre ambas as instâncias na construção do pensamento antropológico.

8 A partir destes dois pólos de atuação (produção do pensamento da escrita em Antropologia/ produção de novas formas de práticas etnográficas no âmbito do espaço livresco), se consolida no BIEV/UFRGS o terceiro pólo de investimento da pesquisa com a escrita antropológica: a montagem de coleções etnográficas escritas sobre o tema da memória coletivas, formas de sociabilidades, cotidiano, narrativas biográficas, itinerários urbanos e trajetórias sociais no mundo urbano contemporâneo, incluindo-se neste vasto patrimônio de fontes e documentos etnográficos reunidos a produção textual dos próprios antropólogos urbanos ao longo de suas pesquisas. Tais coleções devem ser indexadas e catalogadas na base de dados do GT, através do método de convergência, gerando aprendizagens aos próprios pesquisadores do grupo no que diz respeito às condições epistemológicas da produção de conhecimento no âmbito da antropologia das sociedades complexas.

${ }^{9}$ Pensamos aqui em particular no artigo de José Mauricio P. Andion Arruti, Etnografia e Historia no Mocambo: notas sobre uma "situação de perícia", in: Leite, Ilka Boaventura (Org). Laudos periciais antropológicos, p. 113-136, onde o autor trata, por um lado, do tema da apropriação realista dos laudos produzidos por antropólogos pelos sujeitos por eles etnografados e, por outro, do papel da escrita etnográfica como peças de processos judiciais e administrativos.

${ }^{10}$ No espaço livresco, diferente do espaço jurídico-legal, a representação do outro pelo antropólogo é confrontada uma vez que na escritura etnográfica o outro não detém a sua própria fala, não tem o domínio dos seus gestos e posturas descritos pelo antropólogo; torna-se refém do antropólogo e das formas expressivas adotadas por sua comunidade lingüística de origem.

${ }^{11}$ Seguindo-se J. Rancière, no primeiro caso, o da voz do nativo partilhada no trabalho de campo, tem-se o desconhecimento ou o mal-entendido, no segundo, o da circulação da palavra do antropólogo em sua comunidade lingüística (escrita etnográfica), teríamos o desentendimento. Esta última estaria referida à apresentação sensível de um objeto comum, o pensamento do "nativo", que pode ou não ser reconhecido sob a forma desta palavra entre a comunidade antropológica.

${ }^{12}$ E disto que se trata, por exemplo, a polêmica que reúne de um lado, Marshall Sahlins e, de outro, Gananath Obeyesekere, e do qual resultou o livro Como pensam os nativos (Sahlins, 2001). A polêmica entre ambos (do mito europeu da irracionalidade indígena e a racionalidade burguesa dos havaianos) sem dúvida revela que do desentendimento entre os antropólogos podem decorrer, para o caso do nativo, situações úteis ou nocivas para ele tanto quanto podem the trazer coisas boas ou ruins.

${ }^{13}$ As observações de J. Rancière sobre a palavra (logos que manifesta) e a voz (que apenas indica) lembram, sob outra forma, as palavras de Michel de Certeau (2002:212), principalmente quando o autor pondera sobre o caráter político da escrita na história. Ou seja, a escrita como palavra instituída no lugar do outro e destinada a ser escutada de uma forma diferente daquela falada. O autor aprofunda ainda mais esta problemática: $a$ linguagem oral espera, para falar, que uma escrita a percorra e saiba o que ela diz (J. Rancière, 1996:47). 
${ }^{14}$ Isto se coloca como problema quando vemos cada vez mais os antropólogos trabalhando em sua própria sociedade se confrontarem com a oralidade do outro não como marca da sua cultura, mas como estigma de sua exclusão e discriminação pela via do iletrismo.

15 Com isto Michel de Certeau conclui ao final das duas primeiras páginas do capítulo dedicado a escrita etnográfica: a operação escriturária que produz, preserva, cultiva "verdades" não perecíveis, articula-se num rumor de palavras diluídas tão logo enunciadas, e, portanto, perdidas para sempre. Uma "perda" irreparável é $o$ vestígio destas palavras nos textos dos quais são o objeto. É assim que se parece escrever em relação ao outro. Um comentário que para a antropologia contemporânea deveria servir de inspiração para os próprios etnógrafos cada vez mais comprometidos em ajustar o dito/ouvido e a escrita como operação etnográfica, exilando precisamente a inquietação que ela promove para a construção do pensamento antropológico.

${ }^{16}$ Para, J. Rancière, na linguagem figurada se esconde o livro da vida, e é, portanto, no interior da fabulação que o jogo figurado da linguagem faz funcionar a verdade do romance, o que nos remeteria aqui a pensar na tradição do romance que herda o texto etnográfico e nos respectivos jogos figurados de linguagem.

${ }^{17}$ Para M. Foucault (1966) até fins do séc. XVI a semelhança (parecença) desempenhou um papel importante na exegese e na interpretação dos textos sagrados, organizando o jogo de símbolos nas escrituras e permitindo através deles conhecer as coisas visíveis e invisíveis, guiando a arte de representá-los. Em termos "rancierianos", o corpo da letra e a sua verdade conformam a grande sintaxe do mundo onde todas as coisas e os seres se ajustam e se fecham sobre si mesmos, se duplicam, se refletem ou se encadeiam. O livro da vida e o teatro da vida reúnem representação e imitação como construindo o corpo de verdade da letra.

${ }^{18}$ Segundo M. Foucault (1966) na épistème do séc. XVII, a semelhança é "empurrada" para os confins do saber, e o conhecer significa a disposição das palavras e das coisas em quadros ordenados de identidades e diferenças (mathésis, taxonomia, gênese) tendo em vista que ingressamos na ciência das ordens empíricas para a qual o saber requer uma análise do conhecimento e de suas origens. As palavras, na época clássica, receberam a missão e o poder de "representar" o pensamento. A linguagem representa o pensamento como o pensamento representa a linguagem. Linguagem não está mais, com efeito, no exterior do pensamento, mas ela é o próprio do pensamento.

${ }^{19}$ Para o autor este processo da fazer funcionar a verdade de um texto liga-se ao processo de separação, num primeiro tempo, entre o mundo profano, aberto ao saber, e o mundo da fé e, logo após, a subordinação destes dois mundos às realidades da história, à vontade dos príncipes.

${ }^{20}$ Tal catástrofe se aprofunda no séc. XIII, com a unificação filosófica da pessoa, privada do Principio Unificador do sentido, alienando a figura humana em alguns ideais, o da ciência profana "separada", "positiva", e "objetiva", o da ligação entre o ser aos princípios da história e, finalmente, da segregação do sagrado e dos valores culturais em uma casta, uma classe ou sociedade privilegiada.

${ }^{21}$ Para G. Durand instaura-se desde aí a figura do homem da civilização como fenômeno distinto da figura do homem da tradição, aquela que tende a separar o "eu penso" das coisas pensadas, através do divórcio entre a figura humana e o cosmos. Nesta última catástrofe rompe-se a perspectiva de que a função do conhecimento, dos atos e dos pensamentos humanos é a de recondução do ser para além da sua separação do mundo, de que prosa do mundo reside tanto no "eu penso" quanto naquilo que é pensado, sendo a escritura o duplo lingüístico da assinatura. Cria-se cada vez mais uma distância entre os atos humanos, seus pensamentos e o princípio que poderia legitimá-los.

${ }^{22}$ Interessante se pensar as heranças destes princípios da figuração do corpo da letra, da presença da escrita e do livro como significativos ainda hoje para a prática escriturística da etnografia no sentido de que ela para atingir seu corpo de verdade de integrar ao mesmo tempo a encarnação do verbo e ter se submetido à prova do deserto, mas vamos deixar este desafio para o caso de outro ensaio, talvez.

\section{Referências bibliográficas}


BARTHES, R. 2001. "L'Auteur comme absence». In: Brunn, A. (org). L'Auteur, anthologie. Paris : GF-Corpus, texte XXXIII, p. 152-157.

CAPRANZANO, V. 1986. "Hermes dilemma: the masking of subversion in ethnographic description". In: J. Clifford, J \& Marcus, G. (Org.). Writing Cultures: the Poetics and Politics of ethnographic. Berkeley: University of California Press, p. 51-76.

CARDOSO DE OLIVEIRA, R. 2000. O trabalho do antropólogo, Brasília, Paralelo 15, São Paulo, Editora UNESP.

CHARTIER, R.. 1996. Práticas de leitura, São Paulo, Estação liberdade. 1996.

. 1996a. Culture ecrite et société, Paris,Albin Michel.

1999. A aventura do livro, do leitor ao navegador, São Paulo, UNESP.

CLIFFORD, J. 1983. "On the authority ethnographic". Representations, vol. I, $\mathrm{n}^{\mathrm{o}}$ 2, $\mathrm{p}$. 117-146.

DA MATTA, R. 1981. Relativizando. Petrópolis, Vozes.

De CERTEAU, M. 2002. A escrita da Historia, Rio de Janeiro: Forense Universitária. DURAND, G. 1979. Sciencie de 1'homme et Tradition, Paris, Berg. International.

EVANS-PRITCHARD, E.E. 1999. Os Nuer,. São Paulo, Perspectiva.

Janeiro, Jorge Zahar Editores.

. 2005. Azande, bruxaria, oráculos e feitiçaria, Rio de

FOUCAULT, M. 1966. Les mots et les choses, Paris, Plon.

2001. «Qu'est-ce qu'un auteur?» In : Brunn, A. (Org). L'Auteur, anthologie. Paris, GF-Corpus, texte VI, p.76-82a. (publicado originalmente em 1969.)

GEERTZ, Clifford. 1980. Blurred genres. American Scholar 49: p. 165-170.

1991. Negara, o Estado teatro no século XIX, Lisboa, DIFEL.

Editores.

Editoria UFRJ.,

. 2002. Obras e vidas, o antropólogo como autor, Rio de Janeiro,

LEITE, I. B. (org) 2005. Laudos periciais antropológicos em debate, Florianópolis, Coedição NUR/ABA.

LÉVI-STRAUSS C. 1979. Antropologia Estrutural, São Paulo,Tempo Brasileiro.

1982. As estruturas elementares do parentesco, Petrópolis, Vozes.

MALINOWISKI, B. 1989. Les argonautes du Pacifique occidental, Paris, Gallimard.

MARCUS, George E. \& Cushman, Dirck. 1982. «Ethnographies as text”. Annual Review of Anthropology, v. 11, p. 25-69.

MEAD, M. \& BATESON, G. 1962. Balinese's Characters, New York, New York Academy of Sciences.

RABINOW, P. 1986. "Representation are social facts. Modernity and postmodernity in Anthropology." In: J. Clifford, J \& Marcus, G. (Org.). Writing Cultures: the Poetics and Politics of ethnographic. Berkeley: University of California Press, pp. 234-261.

RANCIÈRE, Jacques. 1996. O desentendimento, São Paulo, Editora 34.

1995. Políticas da Escrita, São Paulo, Editora 34.

SAHLINS, Marshall. 1994. Ilhas de Historia, Rio de Janeiro, Jorge Zahar Editores. 2005. Como pensam os nativos, São Paulo, EDUSP.

SIMMEL, Georg. 1935. Cultura femenina y otros ensayos. Madrid, Revista de Occidente.

TAUSSING, M. T. 1980. The devil and commodity fetishism in south America. Chapel Hill: University North Carolina Press. 